\title{
Reasons for tooth extraction in 3-8 year-old Turkish children
}

\author{
Mine Koruyucu $^{1}$, Merve Bayram ${ }^{2}$, Nural Bekiroglu ${ }^{3}$ and Figen Seymen ${ }^{* 1}$ \\ ${ }^{1}$ Istanbul University, Faculty of Dentistry, Department of Pedodontics, Istanbul, Turkey \\ ${ }^{2}$ Medipol University, Faculty of Dentistry, Department of Pedodontics, Istanbul, Turkey \\ ${ }^{3}$ Marmara University, Medical School, Department of Biostatistics, Istanbul, Turkey
}

\begin{abstract}
Objective: Extraction of primary or permanent teeth is performed for several reasons, including caries, periodontal disease, orthodontic treatment, traumatic injures, treatment failure, tooth impaction or eruption. The aim of this study was to investigate the principal reasons for extraction in children aged between 3-8 years.

Methods: The patients selected randomly for this retrospective study were identified by analyzing dental records of 3-8 year-old children receiving dental treatment at Istanbul Univeristy, Faculty of Dentistry, Department of Pedodontics. A total of 825 patients and their panoromic radiographs have been viewed. The patient's age and gender, df, dfs, DMF, DMFS, number of extracted teeth and the reasons for the extraction were recorded.

Results: A total of 1405 (16 permanent, 1389 primary) extractions were performed in 825 (362 female, 463 male) of the patients. Patient's mean ages $6.5 \pm 1.36$. Reasons for extractions were; caries: $72.8 \%$, orthodontics: $0.2 \%$, trauma: $5.9 \%$, periodontal: $0.2 \%$, eruption: $14.9 \%$, treatment failure: $1.7 \%$, other reasons: $4.05 \%$.The mean df,dfs,DMF,DMFS scores were found respectively $5.41 \pm 3.2,9.45 \pm 7.0,0.52 \pm 1.0,0.68 \pm 1.6$. The data were converted to SPSS format, frenquency and Chisquare, $T$ test was used for analysis.
\end{abstract}

Conclusions: The results of this study indicate that caries is the main reason for extraction in 3-8 year-old children. This result may be due to a lack of oral hygiene habits in children aged 3-8.

\section{Introduction}

Extraction of primary or permanent teeth is performed for several reasons, including caries, periodontal disease, orthodontic treatment, traumatic injures, treatment failure, tooth impaction or eruption. Caries is the most common reason for extractions in a majority of the younger age groups. Also periodontal disease is common cause of tooth loss for older patients. The reasons for extractions among teenagers are usually related to orthodontic treatment plans [1-5].

A better knowledge of the reasons for extractions can be a help to optimize dental care and treatment planning and thereby avoid painful events and the possible development of dental anxiety for children. It is also important to find out which treatments had been performed before caries-related extractions, as the aim of restorative treatment is to keep teeth in place during their lifetime of function $[2,3]$.

Several studies have investigated the risk indicators of tooth loss; income, education, oral hygiene practices, smoking and gender are reported factors associated with tooth loss [6]. Thus, controversial findings could be explained by differences in the characteristics of the study population, immunological and genetic factors, cultural beliefs, and socioeconomic characteristics, among others. Immunological and genetic reasons are some of the contributory factors that may explain why some populations exposed to the same bacterial etiologic factors did not develop similar pathological conditions [7].

The aim of this study was to investigate the principal reasons for extraction in Turkish children aged between 3-8 years.

\section{Materials and methods}

The patients selected randomly for this retrospective study were identified by analyzing dental records of 3-8 year-old children receiving dental treatment at Istanbul Univeristy, Faculty of Dentistry, Department of Pedodontics, Istanbul, Turkey. A total of 825 patients and their panoromic radiographs have been viewed. The patient's age and gender, $\mathrm{df}, \mathrm{dfs}, \mathrm{DMF}, \mathrm{DMFS}$, number of extracted teeth and the reasons for the extraction were recorded to anamnesis form by one dentist. The main reason for each tooth extraction was described using a modification of the criteria previously suggested by 8 , excluding preprosthetic reasons and wisdom teeth. The reasons were categorized as:

Caries related reasons, periodontal reasons, orthodontic reasons, trauma, eruption problems, treatment failure and other reasons.

The instructions included questions about criteria for the assignment of extraction. The adopted criteria were based on those used by Ainamo et al., Cahen et al., Kay et al., Agerholm [8-11].

Correspondence to: Figen seymen, Istanbul University, Faculty of Dentistry, Department of Pedodontics 34093, Istanbul/Turkey, Tel: 0090212414202030283; Fax: 0090212 5310515; E-mail: figenseymen@superonline.com

Key words: tooth extraction, children, permanent teeth, primary teeth, caries, dental care

Received: December 30, 2016; Accepted: January 23, 2017; Published: January 26, 2017 
These are:

Caries: Teeth requiring extraction because of caries (initial or recurrent) and its consequences. Extracted root's remnants where the crown was lost through caries and teeth fracturing due to weakening by caries.

Orthodontic treatment: Teeth tobe removed for othodontic treatment (reasons).

Trauma: Teeth extracted due to or as a result of trauma, including jaw fractures.

Periodontal disease: Teeth requiring extraction due to periodontitis including pain, loss of function, loose and supporting teeth.

Eruption problems: Partial impacted and fully impacted teeth and those, which are characterized by pericoronitis (persistent inflammation around third molar, which necessitated removal of one or all third molars).

Treatment failure: Failed restorations and root canal treatment and fracture of teeth weakened by endodontic treatment.

Other: Any other reason, which is not encompassed by one of the above categories.

Additionally, the prevalence of tooth loss was evaluated by reasons of extractions and type of teeth (primary or permanent molars, premolars, incisors and canines).

SPSS software (Statistical Package for Social Sciences) for Windows 15.0 was used for statistical analysis. Descriptive data were expressed by means of numbers and percentages. Chi-square test and Fisher's exact test was used to comparison of qualitative datas. Statistical significance was defined at $\mathrm{p}<0.05$.

\section{Results}

A Total of 1405 (16 permanent, 1389 primary tooth) extractions were performed in 825 (362 female, 463 male) of the patients. The patients were selected randomly between 3-8 aged. Patient's mean ages $6.5 \pm 1.36$. The mean df, dfs, DMF, DMFS scores were found respectively $5.41 \pm 3.2,9.45 \pm 7.0,0.52 \pm 1.0,0.68 \pm 1.6$.

Reasons for extractions were; caries: $72.8 \%$, orthodontics: $0.2 \%$, trauma: $5.9 \%$, periodontal: $0.2 \%$, eruption: $14.9 \%$, treatment failure: $1.7 \%$, other reasons (cyst, supernumerary): $4.04 \%$ (Figure 1).

Caries related extraction were found higher in both gender (M $40.2 \%$, F $32.5 \%$ ). Totaly, extraction was performed in male more than female (Table 1). It was found that frequency of extraction was increasing by age. Most of the dental extractions was determined by the age of 8 years. In 8 -year-old, caries related extraction was found $30.8 \%$ (Table 2). Statistically significant differences were found only between caries related extraction and df, dfs, DMF and DMFS $(\mathrm{p}<0.005)$.

The primary first molars were the most frequently (37.8\%) extracted tooth and at the same time these teeth were extracted due to the caries (34.3\%) damage (Table 3).

Caries, eruption, treatment failure and other reasons related extraction in 6-8 aged group were statistically higher than 3-5 aged group $(\mathrm{p}<0.01, \mathrm{p}<0.05)$. Statistically significant differences was not found between periodontal, orthodontic and trauma related extraction and aged groups ( $\mathrm{p}>0.05)$ (Table 4$)$.

Extraction due to the other reasons in females, significantly higher

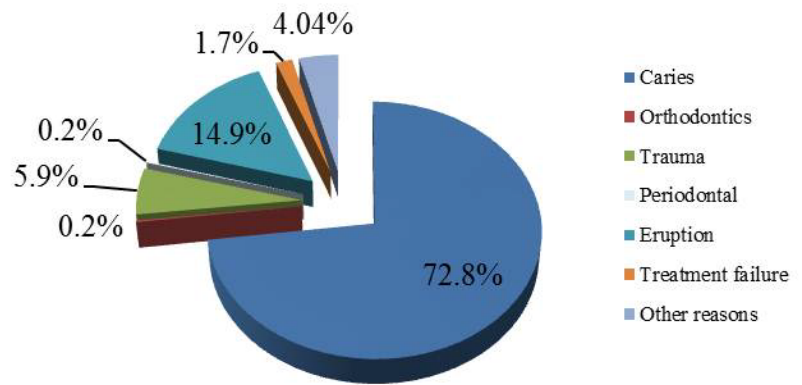

Figure 1. Distribution of extraction reasons.

Table 1. Distribution of extraction reasons according to gender.

\begin{tabular}{|l|c|c|c|}
\hline Gender & $\begin{array}{c}\text { Male } \\
\text { n (\%) }\end{array}$ & $\begin{array}{c}\text { Female } \\
\text { n (\%) }\end{array}$ & $\begin{array}{c}\text { TOTAL } \\
\text { n (\%) }\end{array}$ \\
\hline Caries & $566(40.2)$ & $457(32.5)$ & $\mathbf{1 0 2 3}(\mathbf{7 2 . 8})$ \\
\hline Orthodontics & $1(0.07)$ & $3(0.21)$ & $\mathbf{4}(\mathbf{0 . 2})$ \\
\hline Trauma & $52(3.7)$ & $32(2.2)$ & $\mathbf{8 4}(5.9)$ \\
\hline Periodontal & $3(0.21)$ & $0(0)$ & $\mathbf{3 ( 0 . 2 )}$ \\
\hline Eruption & $127(9)$ & $83(5.9)$ & $\mathbf{2 1 0}(\mathbf{1 4 . 9 )}$ \\
\hline Treatment failure & $15(1.06)$ & $9(0.6)$ & $\mathbf{2 4}(\mathbf{1 . 7})$ \\
\hline Other reasons & $23(1.63)$ & $34(2.4)$ & $\mathbf{5 7}(\mathbf{4 . 0 4})$ \\
\hline TOTAL & $\mathbf{7 8 7}(\mathbf{5 6})$ & $\mathbf{6 1 8 ( 4 3 . 9 )}$ & $\mathbf{1 4 0 5}$ \\
\hline
\end{tabular}

Table 2. Distribution of extraction reasons according to age.

\begin{tabular}{|l|c|c|c|c|c|c|c|}
\hline Age & $\mathbf{3}$ yrs & $\mathbf{4}$ yrs & $\mathbf{5}$ yrs & $\mathbf{6}$ yrs & $\mathbf{7}$ yrs & $\mathbf{8}$ yrs & TOTAL \\
$\mathbf{n}(\mathbf{\%})$ & $\mathbf{n}(\mathbf{\%})$ & $\mathbf{n}(\mathbf{\%})$ & $\mathbf{n}(\mathbf{\%})$ & $\mathbf{n}(\mathbf{\%})$ & $\mathbf{n}(\mathbf{\%})$ & $\mathbf{n}(\mathbf{\%})$ \\
\hline Caries & 1 & $27(1.9)$ & 102 & 158 & 301 & 434 & $\mathbf{1 0 2 3}$ \\
& $(0.07)$ & & $(7.2)$ & $(11.2)$ & $(21.4)$ & $(30.8)$ & $\mathbf{( 7 2 . 8 )}$ \\
\hline Orthodontics & 0 & $2(0.14)$ & 0 & 0 & 0 & $2(0.14)$ & $\mathbf{4}(\mathbf{0 . 2 8})$ \\
\hline Trauma & 1 & $7(0.49)$ & $8(0.56)$ & $24(1.7)$ & $24(1.7)$ & $20(1.42)$ & $\mathbf{8 4}(\mathbf{5 . 9})$ \\
\hline Periodontal & 0 & $2(0.14)$ & 0 & 0 & 0 & $1(0.07)$ & $\mathbf{3}(\mathbf{0 . 2})$ \\
\hline Eruption & 0 & $1(0.07)$ & $2(0.14)$ & $16(1.14)$ & $63(4.48)$ & 128 & $\mathbf{2 1 0}(\mathbf{1 4 . 9})$ \\
\hline $\begin{array}{l}\text { Treatment } \\
\text { failure }\end{array}$ & 0 & 0 & $1(0.07)$ & $4(0.28)$ & $9(0.64)$ & $10(0.71)$ & $\mathbf{2 4}(\mathbf{1 . 7})$ \\
\hline Other reasons & 0 & 0 & $3(0.21)$ & $5(0.35)$ & $7(0.49)$ & $42(2.9)$ & $\mathbf{5 7}(\mathbf{4 . 0 4})$ \\
\hline TOTAL & $\mathbf{2}$ & $\mathbf{3 9}(\mathbf{2 . 7 )}$ & $\mathbf{1 1 6}$ & $\mathbf{2 0 7}$ & $\mathbf{4 0 4}$ & $\mathbf{6 3 7}$ & $\mathbf{1 4 0 5}$ \\
\hline & $\mathbf{( 0 . 1 4 )}$ & & $\mathbf{( 8 . 2 )}$ & $\mathbf{( 1 4 . 7 )}$ & $\mathbf{( 2 8 . 7 )}$ & $\mathbf{( 4 5 . 3 )}$ & \\
\hline
\end{tabular}

than males $(\mathrm{p}<0.05)$. There was no statistically significant differences was found between caries, periodontal, orthodontic, eruption, trauma and gender ( $\mathrm{p}>0.05)$ (Table 5).

\section{Discussion}

Extraction of teeth is a relatively common treatment of pediatric dental practice. The clinical considerations are not the only factors to influence the care provided for dentists' treatment decisions. Attendance patterns affect the treatment provided to children as does health-care policy and the system within which the child receives the dental care. Also the parents' wishes concerning the treatment of their children can play an important role on dentist' treatment/extraction decisions whose name is social indications [6].

Previous studies have shown that dental caries and periodontal disease are the main causes of tooth extraction in several countries.

Caries: Dental caries appears to be the main cause of tooth extraction in a large number of research with the following percentages: $59.0 \%$ [1], 45\% [11], 51\% [12], 49.0\% [13], 55.3\% [14], 43.7\% [3], 31\% 
Table 3. Distribution of extraction reasons according to tooth types.

\begin{tabular}{|c|c|c|c|c|c|c|c|c|}
\hline Number of tooth & $\begin{array}{l}\text { Caries } \\
\text { n (\%) }\end{array}$ & $\begin{array}{c}\text { Orthodontics } \\
\text { n (\%) }\end{array}$ & $\begin{array}{c}\text { Trauma } \\
\text { n (\%) }\end{array}$ & $\begin{array}{c}\text { Periodontal } \\
\text { n }(\%)\end{array}$ & $\begin{array}{l}\text { Eruption } \\
\text { n (\%) }\end{array}$ & $\begin{array}{c}\text { Treatment } \\
\text { Failure } \\
\text { n (\%) }\end{array}$ & $\begin{array}{c}\text { Other } \\
\text { Reasons } \\
\text { n (\%) }\end{array}$ & $\begin{array}{c}\text { TOTAL } \\
\text { n (\%) }\end{array}$ \\
\hline primary central & $36(2.5)$ & 0 & $54(3.8)$ & $1(0.07)$ & $52(3.7)$ & 0 & $6(0.4)$ & $149(10.6)$ \\
\hline primary lateral & $40(2.8)$ & 0 & $25(1.7)$ & $1(0.07)$ & $121(8.6)$ & 0 & $39(2.7)$ & $226(16)$ \\
\hline primary canine & $13(0.9)$ & $4(0.28)$ & $1(0.07)$ & 0 & 0 & 0 & $7(0.4)$ & $25(1.7)$ \\
\hline primary first molar & $483(34.3)$ & 0 & 0 & $1(0.07)$ & $28(1.9)$ & $18(1.2)$ & $2(0.14)$ & $532(37.8)$ \\
\hline primary second molar & $440(31.3)$ & 0 & 0 & 0 & $9(0.6)$ & $6(0.4)$ & $2(0.14)$ & 457 (32.5) \\
\hline permanent central & $1(0.07)$ & 0 & $4(0.28)$ & 0 & 0 & 0 & 0 & $5(0.35)$ \\
\hline permanent lateral & 0 & 0 & 0 & 0 & 0 & 0 & $1(0.07)$ & $1(0.07)$ \\
\hline permanent first molar & $10(0.71)$ & 0 & 0 & 0 & 0 & 0 & 0 & $10(0.71)$ \\
\hline TOTAL & $1023(72.8)$ & $4(0.28)$ & 84 (5.9) & $3(0.21)$ & $210(14.9)$ & $24(1.7)$ & $57(4)$ & 1405 \\
\hline
\end{tabular}

Table 4. Comparisons of extraction reasons according to age groups.

\begin{tabular}{|c|c|c|c|}
\hline & 3-5 aged & 6-8 aged & $p$ \\
\hline & n (\%) & n (\%) & \\
\hline Caries $(n=13434)$ & $130(\% 47,3)$ & $892(\% 77,0)$ & $0,001 * *$ \\
\hline Periodontal $(\mathrm{n}=\mathbf{8 2 6})$ & $2(\% 0,9)$ & $1(\% 0,2)$ & 0,163 \\
\hline Orthodontics $(n=826)$ & $0(\% 0,0)$ & $4(\% 0,7)$ & 0,577 \\
\hline Eruption $(n=926)$ & $3(\% 1,4)$ & $207(\% 29,0)$ & $0,001 * *$ \\
\hline Trauma $(n=861)$ & $16(\% 7,3)$ & $68(\% 10,6)$ & 0,164 \\
\hline Treatment failure $(n=834)$ & $1(\% 0,5)$ & $23(\% 3,7)$ & $0,016^{*}$ \\
\hline Other reasons $(n=843)$ & $3(\% 1,4)$ & $54(\% 8,6)$ & $0,001 * *$ \\
\hline
\end{tabular}

Chi-square, Fisher's Exact test $\quad * p<0.05 \quad * * p<0.01$

Tablo 5. Comparisons of extraction reasons according to gender.

\begin{tabular}{|l|c|c|c|}
\hline \multirow{2}{*}{} & Female & Male & \multirow{2}{*}{$\boldsymbol{p}$} \\
\cline { 2 - 4 } & $\mathbf{n}(\%)$ & $\mathbf{n}(\%)$ & \\
\hline Caries (n=13434) & $456(\% 71,6)$ & $566(\% 71,0)$ & $\mathbf{0 , 8 1 3}$ \\
\hline Periodontal (n=826) & $0(\% 0,0)$ & $3(\% 0,6)$ & $\mathbf{0 , 2 6 1}$ \\
\hline Orthodontics (n=826) & $3(\% 0,8)$ & $1(\% 0,2)$ & $\mathbf{0 , 3 2 5}$ \\
\hline Eruption (n=926) & $83(\% 20,5)$ & $127(\% 24,3)$ & $\mathbf{0 , 1 7 3}$ \\
\hline Trauma (n=861) & $32(\% 8,6)$ & $52(\% 10,7)$ & $\mathbf{0 , 2 9 8}$ \\
\hline Treatment failure (n=834) & $9(\% 2,5)$ & $15(\% 3,2)$ & $\mathbf{0 , 5 3 0}$ \\
\hline Other reasons (n=843) & $34(\% 9,1)$ & $23(\% 4,9)$ & $\mathbf{0 , 0 1 5}$ \\
\hline
\end{tabular}

[6], 70.3\% [15], 59.2\% [16], 56.4\% [17], 50.0\% [18], 46.9\% [19], $43.3 \%$ [20], 49.0\% [10], 35.4\% [21], 20.7\% [22] and 39.5\% [23]. In this study, caries related extraction rates' was found $72.8 \%$ and was higher in children aged 6-8 years. The reason for this, increasing level $\mathrm{df}(\mathrm{s})$, $\mathrm{DMF}(\mathrm{S})$ as a result of poor oral health. Primary incisor was the most frequently extracted tooth type among the youngest children and primary molars most frequently extracted tooth type from the age of 5 years in Scandinavian study [2]. In this study, primary first molar is the most frequently extracted tooth type from the age of 8 years were found.

Periodontal: The percentage of periodontal disease increased in those older than 35 years, males reported more extractions because of periodontal disease, and males also reported more extractions than females older than 35 years. These findings support some epidemiological studies of periodontal disease concluding that men experience more periodontitis than women and that as age increases the prevalence of severe periodontitis increases, in the same study periodontal reasons was found $22.1 \%$ effective for tooth extraction [14]. Ong was found that $35.8 \%$ of the extractions were due to periodontal disease in an Asian population [21]. Another study in Germany showed that $27.3 \%$ of the extractions were due to periodontal reasons [22]. The tooth extraction due to periodontal disease showed a significant increase with age in
Greek population, which is similar to previous studies [24]. Chesnutt et.al were found $21 \%$ tooth extraction related for periodontal disease [12]. In this study, it was thought that extraction due to the periodontal reasons was found $0.2 \%$, because of the younger age group.

Orthodontics: The reasons for extraction among teenagers are usually telated to orthodontic treatment plans. There are several reasons for extractions of primary teeth as a part in an orthodontic treatment plan [2]. Montandon et al. [7], 2012 found that 5.7\%, Caldas [15], 2000 found that $2.5 \%$ level of patients with orthodontic treatment plan related exctraction. In this study, orthodontics was the reason for extraction in $0.2 \%$ of the teeth.

Eruption: Extraction depending on eruption problems for $6.4 \%$ [7]; depending on third molar eruption disorders for 3.7\% [15] and impaction for $12.1 \%$ [14] were reported different researches. In this study we found $14.9 \%$ extraction, related to eruption problems. Especially in the transition period of mix dentition eruption problems are more frequent. So this will be the reason of high percentage.

Trauma: Trauma was the reason for early extraction especially younger age groups. There are different results about this reason as $10.4 \%$ [2]; $2.6 \%$ [7]; $1 \%$ [15]. In this study, trauma was found $5.9 \%$. It can be explained as the age of school time and children will exposed to trauma more in 6-8 aged group.

Treatment Failure: Extraction related to iatrogenic factors were found 9.9\% in Montandon et al [7], 2012 research. A failed dental treatments (e.g. root canal treatments) was recorded $33.4 \%$ in the another study [24]. Our study findings about treatment failure is $1.7 \%$. This results is the lowest percentage in all studies.

Other reasons: Prosthetic indication (3.6\%), and occlusal problems (1.1\%) were found an other reasons in different researches [7]. Caldas et al. also evaluated other reasons for extractions such as prosthetic reasons (6.4\%), and patients request (1\%) [15]. Also few studies have assessed the reasons for tooth extraction based on social class diversities [25]. Cysts and supernumerary teeth were found an other reasons $(4.04 \%)$ in the present study.

\section{Conclusions}

The important factor was age for extraction decision after clinical prognosis in children. The results of this study indicate that caries is the main reason for extraction in 3-8 year-old children in Turkey. This result may be due to a lack of oral hygiene habits in children aged 3-8. The role of the dentists is quite important in maintaining the permanent teeth, especially in this younger aged groups. Also families and children 
informed about oral hygiene habits are very important.

\section{Conflict of interest}

The authors confirm that this article content has no conflicts of interest.

\section{References}

1. Richards W, Ameen J, Coll AM, Higgs G (2005) Reasons for tooth extraction in four general dental practices in South Wales. Br Dent J 198: 275-278.[Crossref]

2. Mansour Ockell N, Bågesund M (2010) Reasons for extractions, and treatment preceding caries-related extractions in 3-8 year-old children. Eur Arch Paediatr Dent 11: 122-130.[Crossref]

3. Al-Shammari KF, Al-Ansari JM, Al-Melh MA, Al-Khabbaz AK (2006) Reasons for tooth extraction in Kuwait. Med PrincPract 15: 417-422.[Crossref]

4. Murray H, Clarke M, Locker D, Kay EJ (1997) Reasons for tooth extractions in dental practices in Ontario, Canada according to tooth type. Int Dent J 47: 3-8.[Crossref]

5. Haddad I, Haddadin K, Jebrin S, Ma'ani M, Yassin O (1999) Reasons for extraction of permanent teeth in Jordan. Int Dent J 49: 343-346.[Crossref]

6. Ak G, Sepet E, Pinar A, Aren G, Turan N (2005) Reasons for early loss of primary molars. Oral Health Prev Dent 3: 113-117.[Crossref]

7. Montandon A, Zuza E, Toledo BE (2012) Prevalence and reasons for tooth loss in a sample from a dental clinic in Brazil. Int J Dent 2012: 719750.[Crossref]

8. Kay EJ, Blinkhorn AS (1986) The reasons underlying the extraction of teeth in Scotland. Br Dent J 160: 287-290.[Crossref]

9. Ainamo J, Sarkki L, Kuhalampi ML, Palolampi L, Piirto O (1984) The frequency of periodontal extractions in Finland. Community Dent Health 1: 165-172.[Crossref]

10. Cahen PM, Frank RM, Turlot JC (1985) A survey of the reasons for dental extractions in France. J Dent Res 64: 1087-1093.[Crossref]

11. Agerholm D (2001) Reasons for extraction by dental practitioners in England and Wales: a comparison with 1986 and variations between regions. J Dent 29: 237-241. [Crossref]

12. Chestnutt IG, Binnie VI, Taylor MM (2000) Reasons for tooth extraction in Scotland. $J$ Dent 28: 295-297.[Crossref]

13. McCaul LK, Jenkins WM, Kay EJ (2001) The reasons for the extraction of various tooth types in Scotland: a 15-year follow up. J Dent 29: 401-407.[Crossref]
14. Lee CY, Chang YY, Shieh TY, Chang CS (2015) Reasons for permanent tooth extractions in Taiwan. Asia Pac J Public Health 27: NP2350-2357.[Crossref]

15. Caldas AF Jr (2000) Reasons for tooth extraction in a Brazilian population. Int Dent J 50: 267-273.[Crossref]

16. Da'ameh D (2006) Reasons for permanent tooth extraction in the North of Afghanistan. J Dent 34: 48-51.[Crossref]

17. Oginni FO (2005) Tooth loss in a sub-urban Nigerian population: causes and pattern of mortality revisited. Int Dent $J$ 55: 17-23.[Crossref]

18. Spalj S, Plancak D, Juric H, Pavelic B, Bosnjak A (2004) Reasons for extraction of permanent teeth in urban and rural populations of Croatia. Coll Antropol 28: 833-839. [Crossref]

19. Sayegh A, Hilow H, Bedi R (2004) Pattern of tooth loss in recipients of free dental treatment at the University Hospital of Amman, Jordan. J Oral Rehabil 31: 124-130. [Crossref]

20. Aida J, Ando Y, Akhter R, Aoyama H, Masui M, et al. (2006) Reasons for permanent tooth extractions in Japan. J Epidemiol 16: 214-219.[Crossref]

21. Ong G (1996) Periodontal reasons for tooth loss in an Asian population. $J$ ClinPeriodontol 23: 307-309.[Crossref]

22. Reich E, Hiller KA (1993) Reasons for tooth extraction in the western states of Germany. Community Dent Oral Epidemiol 21: 379-383.[Crossref]

23. Anand PS, Kuriakose S (2009) Causes and patterns of loss of permanent teeth among patients attending a dental teaching institution in south India. J Contemp Dent Pract 10: E057-064.[Crossref]

24. Chrysanthakopoulos NA (2011) Periodontal reasons for tooth extraction in a group of greek army personnel. J Dent Res Dent Clin Dent Prospects 5: 55-60.[Crossref]

25. Bernabé E, Marcenes W (2011) Income inequality and tooth loss in the United States. $J$ Dent Res 90: 724-729.[Crossref]

Copyright: (C2017 Koruyucu M. This is an open-access article distributed under the terms of the Creative Commons Attribution License, which permits unrestricted use, distribution, and reproduction in any medium, provided the original author and source are credited. 